\author{
E. O. Ezugwu \\ London South Bank University, \\ School of Engineering \\ Machining Research Centre, 103 Borough Road \\ London, SE1 OAA, England. \\ ezugwueo@|sbu.ac.uk
}

\section{High Speed Machining of Aero-Engine Alloys}

Materials used in the manufacture of aero-engine components generally comprise of nickel and titanium base alloys. Advanced materials such as aero-engine alloys, structural ceramic and hardened steels provide serious challenges for cutting tool materials during machining due to their unique combinations of properties such as high temperature strength, hardness and chemical wear resistance. These materials are referred to as difficult-to-cut since they pose a greater challenge to manufacturing engineers due to the high temperatures and stresses generated during machining. The poor thermal conductivity of these alloys result in the concentration of high temperatures at the toolworkpiece and tool-chip interfaces, consequently accelerating tool wear and increasing manufacturing cost.

The past decade has witnessed a radical approach to product manufacture, particularly in the developed economy, in order to remain competitive. Modern manufacturing philosophies, principles and techniques geared primarily towards reducing non value added activities and achieving step increase in product manufacture have been widely adopted. Recent advances in the machining of aero-engine alloys include dry machining at high speed conditions, the use of high pressure and/or ultra high pressure coolant supplies, minimum quantity lubrication, cryogenic machining and rotary (self-propelled) machining technique. Tool materials with improved hardness like cemented carbides (including coated carbides), ceramics, polycrystalline diamond and polycrystalline cubic boron nitride are the most frequently used for high speed machining of aero-engine alloys. These developments have resulted to significant improvement in the machining of aeroengine alloys without compromising the integrity of the machined surfaces. This paper will provide an overview on these recent developments and their application in the aerospace industry.

Keywords: Nickel alloys; titanium alloys; self-propelled rotary tooling, high pressure coolant supply, minimum quantity lubrication, cryogenic cooling, tool wear; and temperature reduction

\section{Introduction}

Machinability is the term used to describe how easily a material can be cut to the desired shape (surface finish and tolerance) with respect to the tooling and machining processes involved. In a machining operation tool life achieved, metal removal rate, component forces and power consumption, surface finish generated and surface integrity of the machined component as well as the shape of the chips can all be used to measure machinability. The machinability index can be significantly affected by the properties of the material being machined, properties and geometry of the cutting tool, cutting conditions employed and other miscellaneous factors such as rigidity of the machine tool, cutting environment, etc. Machining productivity can be significantly improved by employing the right combination of cutting tools, cutting conditions and machine tool that will promote high speed machining without compromising the integrity and tolerance of the machined components. This is particularly essential for the economic machining of difficult-to-cut aero-engine alloys whose peculiar characteristics generally impair machinability.

The driving force for the continual development of many materials over the years is the need for harder, stronger, tougher, stiffer, more corrosion resistant or oxidation resistant material that can also exhibit high strength to weight ratio, in the case of aeroengine alloys. The wide spread use of jet engine has increased demand for materials that have excellent high temperature mechanical and chemical properties relative to steels and stainless steel alloys originally employed in jet engine applications. Demand for hotter, more powerful and more efficient engines led to the

Presented at COBEF 2003 - II Brazilian Manufacturing Congress, 18-21 May 2003, Uberlândia, MG. Brazil.

Paper accepted October, 2003. Technical Editor: Alisson Rocha Machado. development of "super-stainless" alloys, or superalloys, Figure 1 (1). There was a steady increase in typical engine temperature from 1910 till the 1980 s while the 1990 s till date witnessed almost a twofold increase in engine temperature. New materials are becoming available that allow the engine temperature to increase at a rate of almost $10{ }^{\circ} \mathrm{C}$ per annum since the 1950s. Engine efficiency increases and fuel consumption decreases with each increase in temperature.

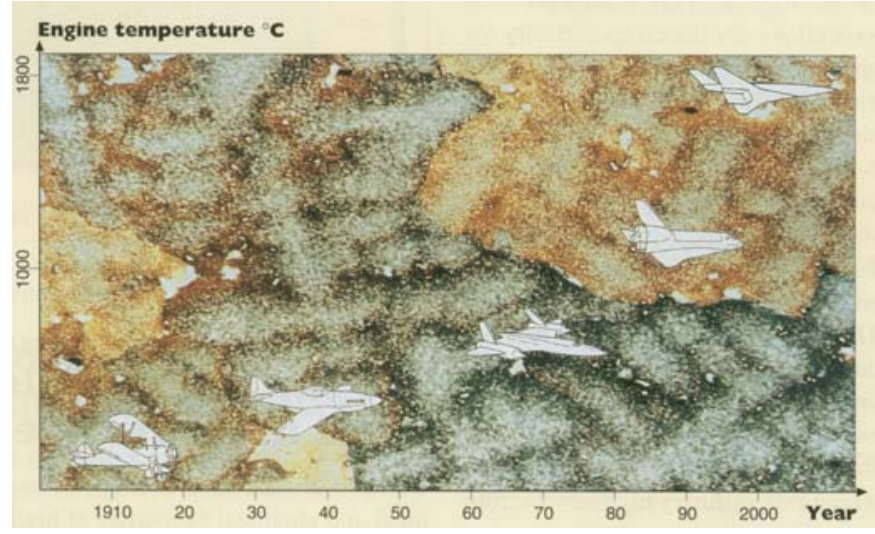

Figure 1. Evaluation of the high temperature strength of material usage in jet engines over the passed century. (After Seco Technical guide, Turning Difficult-To-Machine Alloys).

Heat resistant alloys with high melting temperatures are major materials used in the manufacture of aero-engine components. These exotic superalloys can be grouped into four major categories: Nickel base alloys; cobalt base alloys; iron base alloys (e.g. high chromium stainless steel); and titanium alloys. Figure 2 shows that two-thirds of superalloy production is consumed by the aerospace industry for the manufacture of jet engines and associated components, mainly 
in the hot end of aircraft engines and land based turbines (1). Ability to retain high mechanical and chemical properties at elevated temperatures make superalloys ideal materials for use in both rotating and stationary components in the hot end of jet engines. Components produced with superalloys are smaller and lighter than if they were made of conventional steel. This results in significant fuel savings and reduction in pollution. Each kilogram weight reduction typically results in a US\$150,000 savings in fuel cost over the life of the engine. The remaining third of superalloy production is used by the chemical, medical and structural industries in applications requiring extraordinary high temperature properties and/or exceptional corrosion resistance.

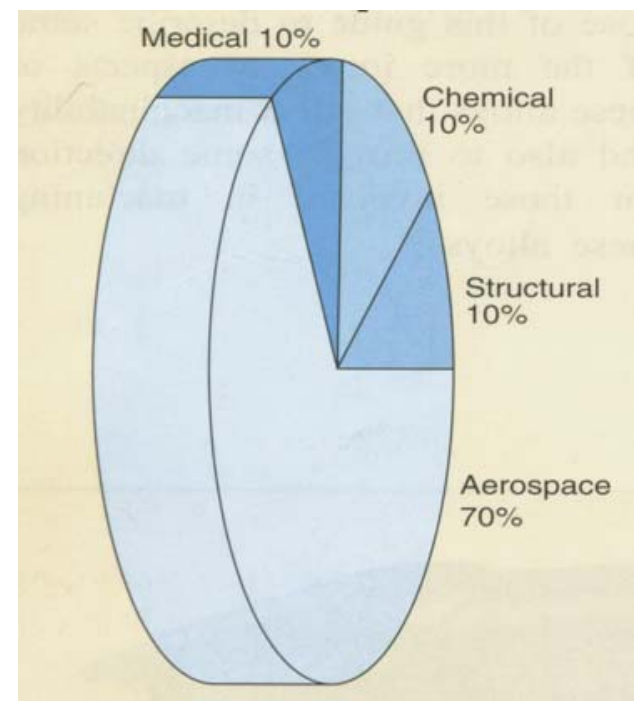

Figure 2. Superalloy consumption (After Seco Technical guide, Turning Difficult-To-Machine Alloys).

About 50 wt.\% of aero-engine alloys are nickel base alloys (2). They exhibit higher strength to weight ratio, relative to steel that is denser. Nickel base superalloys are also used for other applications such as marine equipment, nuclear reactors, petrochemical plants, food processing equipment and pollution control apparatus. They are used in these aggressive environments because of their ability to maintain high resistance to corrosion, mechanical and thermal fatigue, mechanical and thermal shock, creep and erosion at elevated temperatures. Table 1 illustrates schematically how the attractive properties of nickel base alloys are achieved. Similar patterns are followed for iron and cobalt base alloys. Titanium alloys were developed in order to satisfy the need for a class of strong and lightweight materials for aircraft engine and airframe manufacture, because of their outstanding strength to density ratios. They possess exceptional resistance to corrosion, which provide savings on protective coating like paints that will otherwise be used in the case of steel. Titanium alloys can also be used as airframe structure where the operating temperature exceeds $130{ }^{\circ} \mathrm{C}$, the conventional maximum operating temperature for aluminium alloys $(3,4)$. In aero-engines, titanium alloys are widely used in both low and high pressure compressors and for components subjected to high centrifugal loads such as disks and blades that have reduced flow diameters as well as for components which operate under severe fatigue conditions (5). They are also widely used in many other industries because of their good corrosion resistance as well as a range of mechanical and physical properties that can be developed. The main use of iron base superalloys, that are weaker at elevated temperatures than nickel alloys, are in chemical processing applications such as heat exchanger, piping, retorts, mixing tanks, heat treatment equipment, muffles, conveyors, baskets and boxes
(1). The melting temperature of cobalt base alloys are higher than nickel or iron base alloys, hence they are widely used in turbine vane applications as well as where corrosion resistance is of vital importance e.g. orthopaedic applications in the medical industry.

Table 1. Schematic illustration of the various desirable properties achievable for nickel base alloys. (After Seco Technical guide, Turning Difficult-To-Machine Alloys).

\begin{tabular}{|c|c|}
\hline Nickel & Why \\
\hline $\begin{array}{c}\text { Chromium, Iron, Molybdenum, } \\
\text { Tungsten, Tantalum } \\
+\end{array}$ & Higher strength \\
Aluminium, Titanium & \\
+ & High temperature strength \\
Aluminium, Chromium, Tantalum & Oxidation resistance \\
+ & \\
Boron, Carbon, Zirconium & Creep resistance \\
+ & \\
Hafnium & Intermediate temperature \\
& ductility; \\
& Prevents oxide flaking \\
\hline
\end{tabular}

Aero-engine alloys are typically available in cast, wrought and forged, and in sintered (powder metallurgy) forms (Table 2). Components produced from casting techniques exhibit excellent creep strength combined with toughness. These characteristics create machinability problems due to poor chip segmentation. Wrought and forged components generally possess higher strength, better fatigue and fracture resistance. They are, however, more abrasive with greater tendency to deform the tool during machining. More complicated and near net shape alloys can be produced using the powder metallurgy technique. Components from this manufacturing route exhibit extremely low machinability and are very abrasive.

Table 2. Commercial processing techniques of superalloys and their characteristics. (After Seco Technical guide, Turning Difficult-To-Machine Alloys).

\begin{tabular}{|l|l|l|}
\hline $\begin{array}{l}\text { Product } \\
\text { Type }\end{array}$ & Characteristics & $\begin{array}{l}\text { Machinability } \\
\text { Problems }\end{array}$ \\
\hline Castings & $\begin{array}{l}\text { Excellent creep strength } \\
\text { Tough }\end{array}$ & $\begin{array}{l}\text { Difficult to break } \\
\text { chips }\end{array}$ \\
\hline $\begin{array}{l}\text { Wrought } \\
\text { and Forged }\end{array}$ & $\begin{array}{l}\text { Higher strength } \\
\text { Better fatigue and } \\
\text { fracture resistance }\end{array}$ & $\begin{array}{l}\text { More abrasive } \\
\text { Greater tendency to } \\
\text { deform tool }\end{array}$ \\
\hline $\begin{array}{l}\text { Powder } \\
\text { Metallurgy }\end{array}$ & $\begin{array}{l}\text { Can make more } \\
\text { complicated alloys } \\
\text { Near net shape }\end{array}$ & $\begin{array}{l}\text { Extremely low } \\
\text { machinability } \\
\text { Very abrasive }\end{array}$ \\
\hline
\end{tabular}

Typical characteristics of aero-engine superalloys include:

- Austenitic matrix which promote rapid work hardening;

- Retention of high strength levels at elevated temperatures;

- Reactivity with cutting tool materials under atmospheric conditions;

- Tendency to form Built-Up-Edge and weld onto cutting tools;

- Presence of Abrasive carbides in their microstructures;

- Generally low thermal conductivity.

These characteristics cause rapid flank wear, crater wear and notching at the tool nose and/or depth of cut region (Figure 3). The high temperature properties of aero-engine alloys unfortunately have pronounced adverse effect on their machinability. Increase in high temperature strength of the alloys make them harder and stiffer at 
the cutting temperature, thus increasing forces at the cutting edge during machining and consequently promoting chipping or deformation of the tool edge. The low thermal conductivity of the high strength materials will generate very high cutting temperatures during machining. The high temperature strength, toughness and ductility of aero-engine alloys seriously impair chip segmentation. Modification of the as cast or solution treated properties of the alloys by heat treatment often forms abrasive carbide precipitates or second phase particles which accelerate wear at the tool cutting edge. Rapid work hardening of most aero-engine alloys during machining creates a hardened surface that usually promotes notching of the cutting tool as well as making it difficult to maintain precision tolerances or the critical metallurgical integrity of the machined component. The fatigue property of a component can be compromised by a damaged surface. This is why the edge conditions of cutting tools are very important when machining superalloys. All these factors clearly show that cutting tools encounter tremendous heat, pressure and abrasion during machining operation.

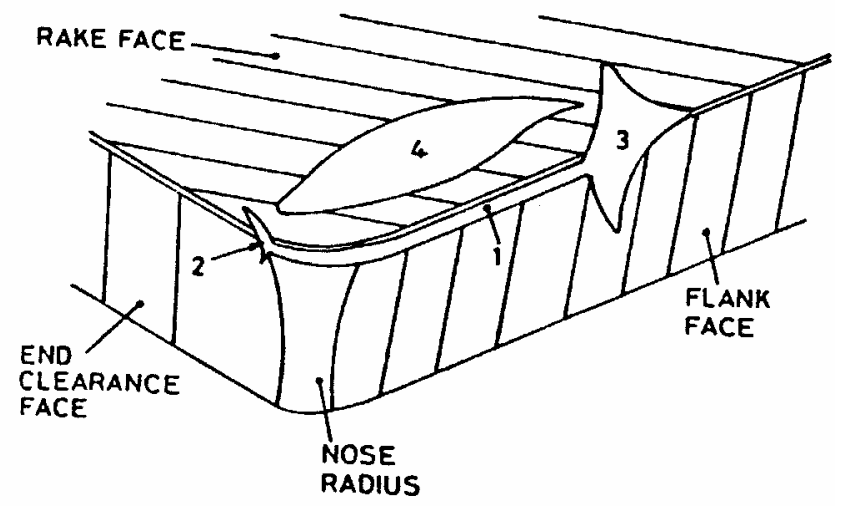

Figure 3. Typical tool wear features.

The machinability of aero-engine alloys will continually decline as service demands increase in order to satisfy the demand for higher temperature capability for structural engine alloys. There is increasing use of single crystal alloys and directionally solidified eutectics (reinforced with long carbide fibres). Other intermetallics are being investigated and will be extremely difficult to machine. Recent improvements, that have also impaired machinability, include the new isothermal forging techniques and other thermalmechanical techniques for producing either near net shape parts or components with improved thermal and structural stability and uniformity.

Titanium aluminides are one of the most exciting new alloys recently introduced for aerospace as well as for automotive applications primarily because of their impressive high temperature properties. In fact, the very impressive high temperature properties of these alloys position them adequately to compete with nickel base alloys in the hot sections of aircraft engines as well as in automobile engine valves. Like most new materials, titanium aluminides are extremely difficult to machine. The toughness, high temperature properties and fatigue properties of conventional alloys and their derivatives are being improved by new processing techniques such as super plastic forming and advance powder metallurgy processing techniques.

\section{Machining of Difficult-to-Cut High Temperature Superalloys}

Table 3 contain practical guides for the machining of high temperature alloys. The hardness of many nickel and titanium alloys increases significantly upon heat treatment, hence they are referred to as age hardenable. Formation of the second phase particles makes the alloy both stronger and more abrasive and thus more difficult to machine. Advantage, therefore, lies in machining in the softer state. Typically, the component is machined to near finish dimensions in the solution treated condition, then age hardened, and then finally finish machined to generate the desired surface finish and to eliminate any distortion associated with heat treatment.

Table 3. Practical guide for machining high temperature alloys. (After Seco Technical guide, Turning Difficult-To-Machine Alloys).

1. Machine alloys in the softest state possible

2. Use a positive rake insert or groove

3. Use relatively sharp edges

4. Use strong geometry

5. Use a rigid set-up

6. Prevent part deflection

7. Use a high lead angle

8. When more than one pass is required, vary the depth of cut

A positive rake cutting edge is recommended for semi-finishing and finishing operations whenever possible. Positive rake geometry minimises work hardening of the machined surface by shearing the chip away from the work piece in an efficient way in addition to minimising built-up-edge. Very light hones or even sharp insert edges are useful in preventing material build-up and improving surface finish during machining. Dull or improperly ground edges increases cutting forces during machining, causing metal build-up, tearing and deflection of the work material. It is however important to note that sharp insert edges are more fragile and susceptible to chipping during machining, thus honed edges are recommended for most roughing operations where concerns about surface roughness are at a minimum. Sharp edges are then used for finishing operations.

Using a large nose radius wherever part geometry does not demand otherwise can reinforce the cutting edge. This has the effect of subjecting more of the tool edge into the cut, decreasing the force at any one point, and preventing localised damage. Machining with a rigid set-up prevents vibration and subsequent chatter that deteriorates surface finish and can cause tool fracture. Tighter tolerance can be maintained with rigid set-ups. Deflection of the work material should be prevented, especially when machining thin walled components or parts made of titanium alloys. Special precautions like the use of filler metals, special fixturing, or back up may be used to prevent movement during machining.

Notching, particularly at the depth of cut line, can be minimised by machining with tools with high leading edge angles as more of the cutting edge is engaged in the cut, thus spreading the wear over a larger distance. Employing the ramping or taper turning technique can also eliminate notching during machining. This involves gradual alteration of the depth of cut (using CNC programme) as the tool traverses along the cutting length, thus spreading the wear along the entire insert edge. This machining technique generally reduces tool wear rate and also prolongs tool life. 


\section{Tool Materials for Machining Aero-Engine Alloys}

Cutting tool materials often encounter extreme thermal and mechanical stresses close to the cutting edge during machining due to the poor machinability of aero-engine alloys. This usually results to plastic deformation and accelerated tool wear. A major requirement of cutting tool materials used for machining aeroengine alloys is that they must possess adequate hot hardness to withstand elevated temperatures generated at high speed conditions. Most cutting tool materials lose their hardness at elevated temperatures resulting in the weakening of the inter-particle bond strength and consequent acceleration of tool wear. The softening temperature of commercially available cutting tool materials used for machining aero-engine alloys is given in Table 4 while Figure 4 illustrates the effect of temperature on the hardness of some cutting tool materials $(6,7)$. Coated carbide tools, ceramics, CBN/PCBN and PCD tools are generally used for high speed machining of aeroengine alloys. Ceramics and $\mathrm{CBN} / \mathrm{PCBN}$ tools are not usually recommended for machining titanium alloys because of their poor performance due to excessive wear rates as a result of the high reactivity of titanium alloys with ceramics, Figure $5(6,8)$.

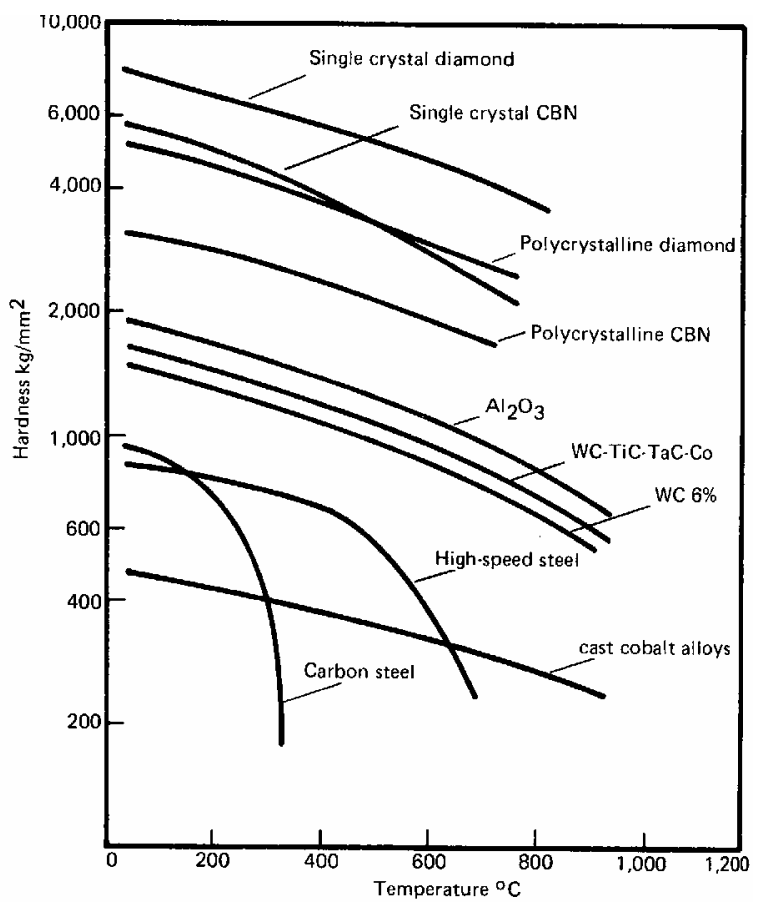

Figure 4. Typical hot hardness characteristics of some tool materials. (After Almond, Proceedings of the International Conference on Improved Performance of Tool Materials, April 28-29, 1981, pp 161-169).

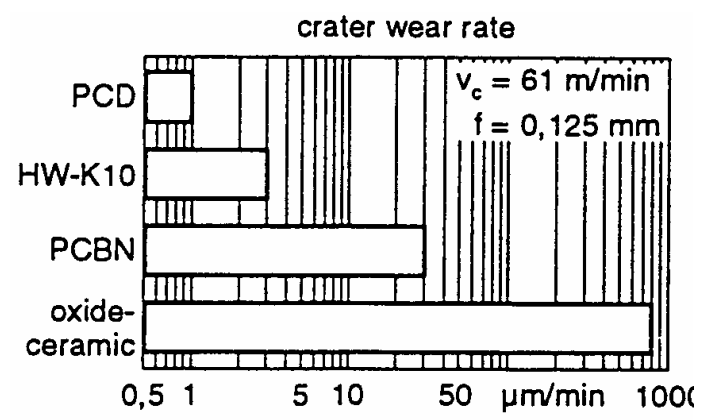

Figure 5. Wear-relevant properties of Ti-6Al-4V and comparison of cutting tools. (After Klocke, Konig et. al. Advanced Manufacturing Systems and Technology, CISM Courses and Lectures No. 372, Springer Verlag, Wien New York, 1996, pp 7-21).
Table 4. Softening Points of Tool Materials. (After Kramer, Journal of Engineering for Industry, 109 (1987) 87-91).

\begin{tabular}{|l|c|}
\hline Tool Materials & $\begin{array}{c}\text { Softening Point Temperature } \\
\left({ }^{\mathbf{0}} \mathbf{C}\right)\end{array}$ \\
\hline High Speed steel & 600 \\
\hline Cemented Carbide $(\mathrm{WC})$ & 1100 \\
\hline Aluminium Oxide $\left(\mathrm{Al}_{2} \mathrm{O}_{3}\right)$ & 1400 \\
\hline Cubic Boron Nitride $(\mathrm{CBN})$ & 1500 \\
\hline Diamond & 1500 \\
\hline
\end{tabular}

Efficient and economic machining of aero-engine alloys under high speed conditions requires a good understanding of the cutting tool materials, cutting conditions, processing time and the functionality of the machined component. Advances in cutting tool materials and machining techniques have resulted to significant increase in metal removal rate when cutting difficult-to-cut aeroengine alloys. These alloys can now be economically machined at higher speed conditions with recently developed cutting tools and machining techniques. Major improvements in the machining of aero-engine alloys, particularly within the past decade are summarised below:

\section{Self-Propelled Rotary Tooling (SPRT)}

Movement of the cutting edge in addition to the main cutting and feed motions is the major difference between rotary cutting and conventional cutting, Figure $6(8,9)$. The additional movement of the rotary tool ensures that a portion of the tool cutting edge is involved in machining operation for a very brief period, followed by a prolong rest period that permits the conduction of thermal energy, associated with the cutting process, away from the cutting zone. Tool rotation is enhanced either by an external driver (in the case of driven rotary tool, DRT) or by the self-propelled action of cutting forces (for SPRT) exerted on the tool by adjusting its axis at an inclination with respect to the cutting speed (10). SPRT employs round inserts rotating continuously about its axis as a result of the driving motion impacted by the cutting force, thus minimising the effect of thermal energy along the entire edge and preventing excessive heating of a particular portion of the insert edge. The much reduced tool-workpiece contact time in rotary cutting permits conduction of minimum amount of energy into the machined component, consequently minimising the surface abuse associated with the cutting process. Much higher cutting speeds and feed rates can be achieved when machining aero-engine alloys with SPRTs, relative to conventional cutting tools, without pronounced adverse effect on tool life and machining performance due to the lower cutting temperature generated, Figure $7(11,12)$.

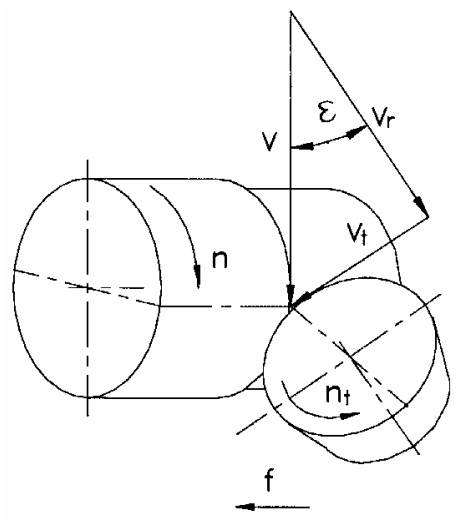

Figure 6. The principle of Rotary cutting. (After Wang, Ezugwu and Gupta, Tribology Transactions, 41, 9 (1998), 2, 289-295). 


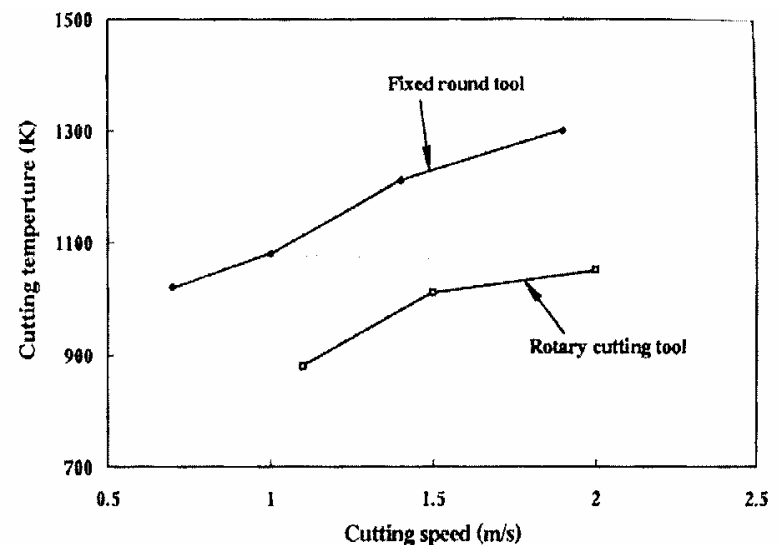

Figure 7. Cutting temperatures. (After Wang, Ezugwu and Gupta, Tribology Transactions, 41, 9 (1998), 2, 289-295).

Extremely low flank wear rate occur when machining titanium alloy with straight grade $(\mathrm{WC} / \mathrm{Co})$ carbide inserts, even at higher speed conditions, Figure 8 . The superior wear resistance characteristics, hence longer tool life, of SPRT tool when machining titanium alloy in relation to those used under conventional cutting action is illustrated in Figure 9 (13). This behaviour can be attributed to the reduced cutting temperature encountered in SPRT. Machining with a rotating tool generates lower cutting temperature, up to $200^{\circ} \mathrm{C}$ lower, than with a non rotating tool due to reduced work done in deformation and friction on the rake face of the tool as well as improved heat transfer from the cutting zone due to rotary action of the tool (12). Employing the entire edge of the round insert during machining can also reduce the rate of tool wear. The cutting edge of the rotary tool shifts continuously during machining significantly reducing the tool-workpiece contact time.

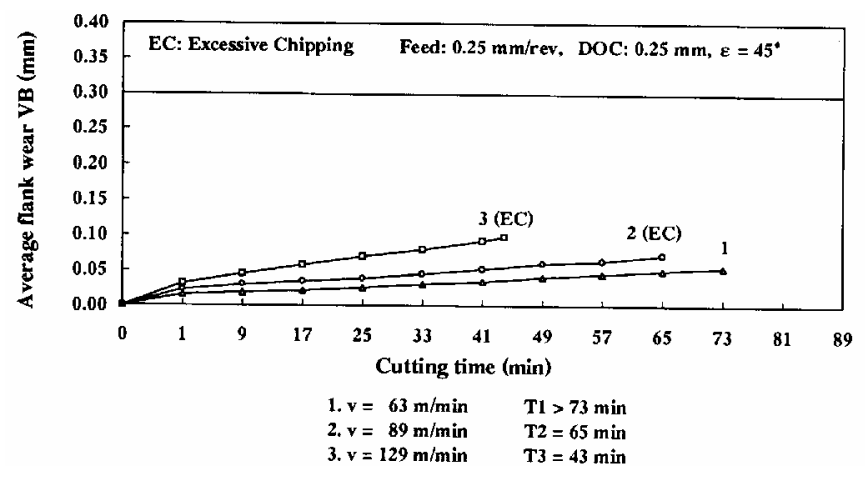

Figure 8. Average flank wear vs. cutting time when machining IMI 318 with the SPRT. (After Wang, Ezugwu and Gupta, Tribology Transactions, 41, 9 (1998), 2, 289-295).

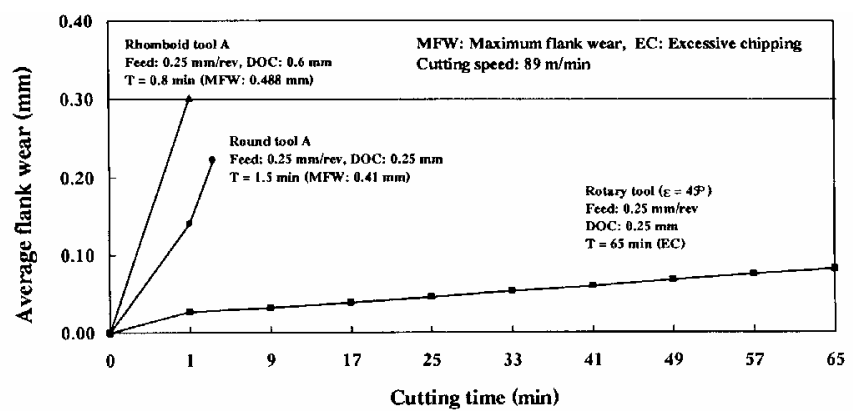

Figure 9. Comparison of wear characteristics when machining IMI 318 with various cutting tools. (After Wang, Ezugwu and Gupta, Tribology Transactions, 41, 9 (1998), 2, 289-295).
Over 60-fold improvement in tool life has been reported when machining a titanium alloy (Ti6Al4V) with SPRT at a cutting speed of $89 \mathrm{~m} / \mathrm{min}$, Figure 10 . This figure also illustrates the capability of the SPRT at much higher cutting speed of $129 \mathrm{~m} / \mathrm{min}$, beyond the capability of the conventional tools. Analysis of the V-L curves in Figure $10 \mathrm{~b}$ shows that the tool life line is marginally affected by increasing cutting speed. This suggests that thermally related wear mechanisms, like diffusion and plastic deformation, have been greatly suppressed when machining IMI 318 alloy with the SPRT. The worn inserts were mainly rejected due to excessive chipping, cracks and welding of the work material at the insert edge as illustrated in Figure 11 (13). These failure modes can be attributed to cyclically fluctuating thermal and mechanical shock induced by continuous shifting of the cutting edge during machining. Welding of the work material to the cutting edge promotes chipping of the rotary tool by altering the geometry of the cutting edge. The adhered chip(s) are usually squashed on re-entry during rotary machining, causing pullout plucking of individual particles or aggregates of tool material on the cutting edge, typical of attrition wear mechanism.

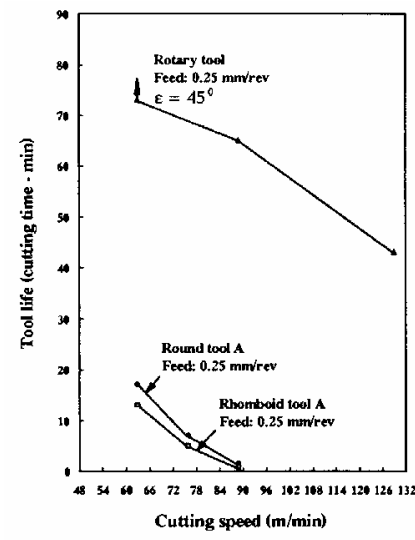

(a) V.T curves

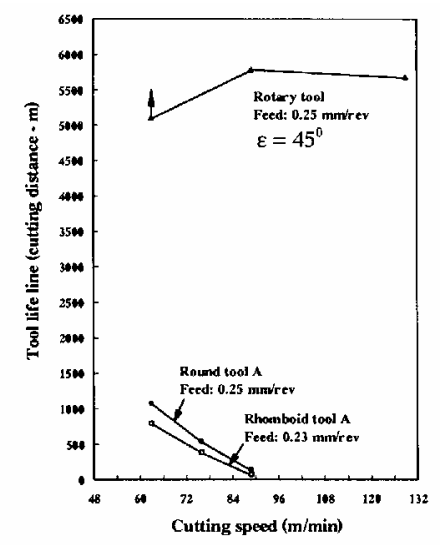

(b) V-L curves
Figure 10. Tool life and tool life line as a function of cutting speed when machining IMI 318 with various cutting tools. (After Wang, Ezugwu and Gupta, Tribology Transactions, 41, 9 (1998), 2, 289-295).

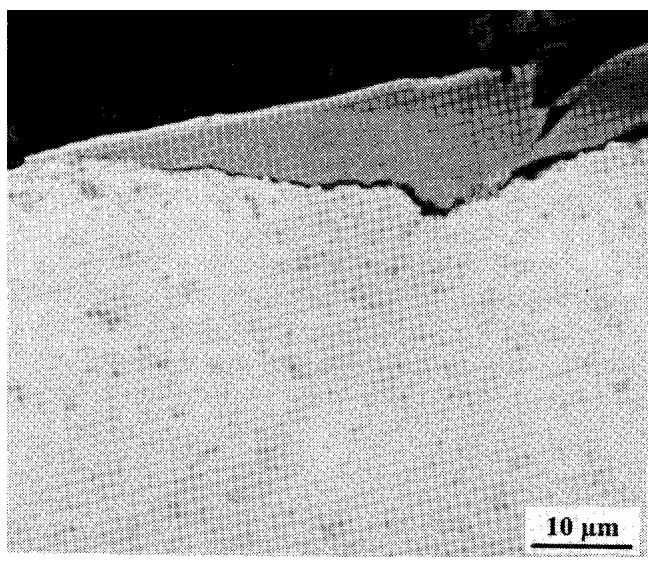

Figure 11. Magnified section of the worn Tool showing the extent of chipping, adhesion of the work piece materials and cracks close to the cutting edge. (After Ezugwu, Olajire and Wang, Proc Instn Mech Engr, Vol 216, Part B (2002), 891-897).

A fitted exponential wear model when machining the titanium, IMI 318, alloy show that about $97 \%$ of the average flank wear rate of SPRT inserts can be attributed to the joint effect of cutting speed, feed rate and inclination angle, $\varepsilon$, of the SPRT (14). Figure 12 shows the effect of cutting speed, feed rate and inclination angle on the 
performance of SPRT tipped inserts. Machining with a higher feed rate generally reduced tool life due to the joint effect of cutting forces and the higher cutting temperatures generated to enhance the chipping action observed on the worn tools. Figure 12 also shows that longer tool life can be achieved by increasing the inclination of the cutting edge, $\varepsilon$, from 45 to $60^{\circ}$. Increase in inclination angle from 45 to $60^{\circ}$ improved tool life by approximately $15 \%$, Figure 13 . Figure 6 shows that the rotary speed, $V_{t}$, of a SPRT tipped insert increases with increasing inclination angle, $\varepsilon$, of the cutting edge, while its relative cutting speed, $\mathrm{V}_{\mathrm{r}}$, decreases as a function of $\mathrm{V} \cos$ $\varepsilon$. Improved performance, in terms of tool life, can therefore be achieved as a result of the inherent low temperature generated when machining with rotary tools, owing to the increased rotary speed and the lower relative cutting speed. It has also been reported that the tangential, $F_{c}$, and radial, $F_{r}$, component forces dropped by $15-20 \%$ and $25-35 \%$ respectively when machining with SPRT inserts because of the reduced amount of work done in chip formation and the lower friction at the tool rake face $(13,14)$.

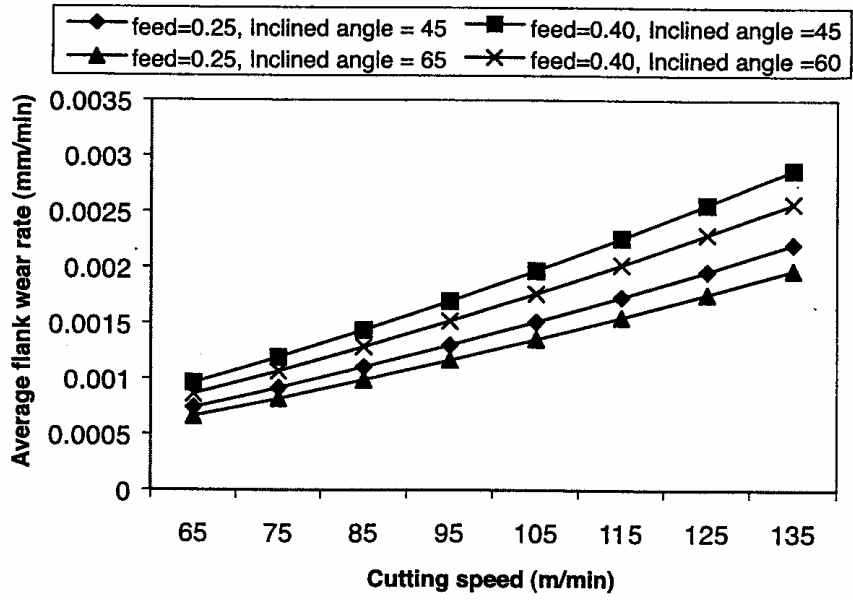

Figure 12. Effect of speed, feed rate and inclination angle $\varepsilon$ on the performance of SPRT-tipped inserts. (After Ezugwu, Olajire and Wang, Proc Instn. Mech. Engr, Vol 216, Part B (2002), 891-897).

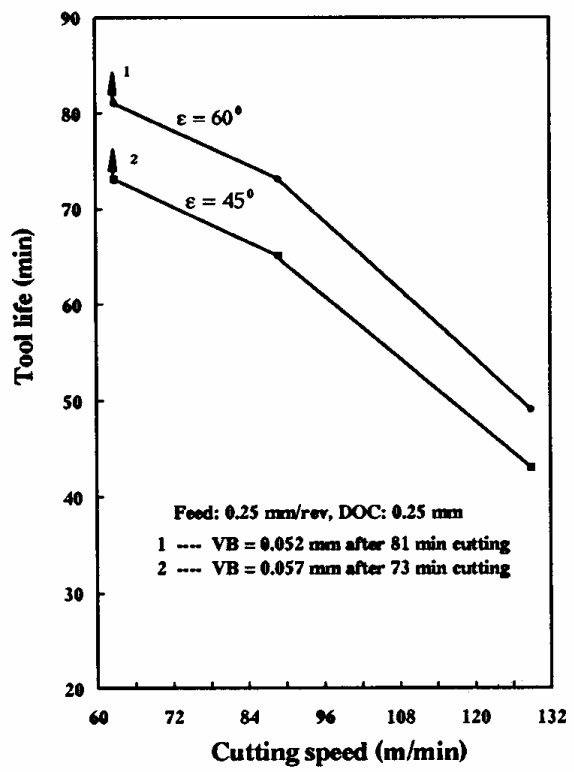

Figure 13. Effect of cutting speed and inclination angle on machining performance of IMI 318 with SPRT. (After Wang, Ezugwu and Gupta, Tribology Transactions, 41, 9 (1998), 2, 289-295).
Flank wear is the dominant failure mode when machining nickel base, Inconel 718, with the SPRT and generally increases with prolong machining, Figure 14. Figure 15 shows that machining with SPRT inserts increased machining productivity by between 100 $200 \%$ at a feed rate of $0.4 \mathrm{~mm} / \mathrm{rev}$ when compared with 0.25 $\mathrm{mm} / \mathrm{rev}$ used for round and rhomboid inserts. This improvement is not as remarkable as when machining the titanium base, IMI 318, alloy due to severe attrition and abrasion wear mechanisms during rotary cutting. These wear mechanisms are enhanced by inherent vibration caused by the low stiffness of the rotary cutting system and the eccentricity of the circular cutting edge. Wear on the rotary tool can also be accelerated by the high work hardening tendency of Inconel 718 and the high abrasion wear due to the presence of hard carbide in the superalloy.

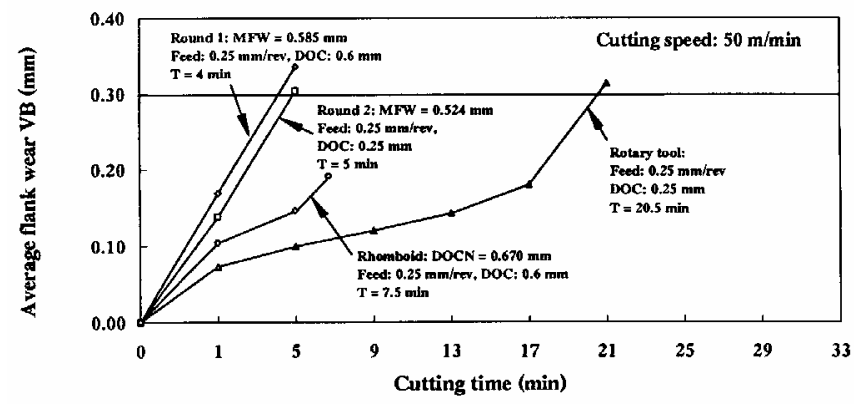

Figure 14. Comparative wear performance. (After Wang, Ezugwu and Gupta, Tribology Transactions, 41, 9 (1998), 2, 289-295).
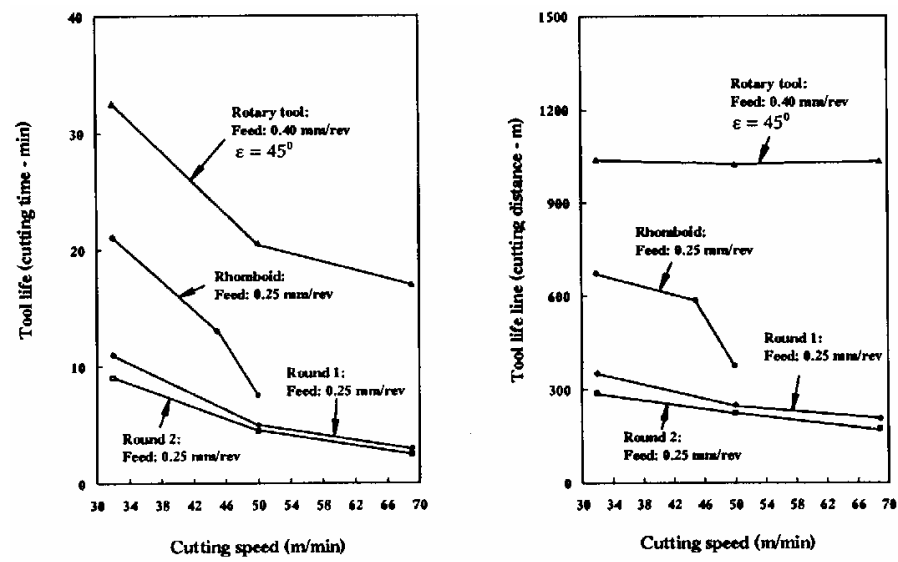

Figure 15. Comparative tool life performance. (After Wang, Ezugwu and Gupta, Tribology Transactions, 41, 9 (1998), 2, 289-295).

A remarkable feature of surfaces created when machining with SPRT is that the cutting trace was at an angle (referred to as the cutting trace angle, $\lambda$ ) to the nominal cutting direction, Figure 16 (14), contrary to the machined surfaces generated under conventional turning where the cutting trace coincides with the cutting direction. The existence of friction in the rotary system makes the cutting trace angle, $\lambda$, to always be smaller than the inclination angle, $\varepsilon$. Variation in cutting speed and feed rate has a corresponding effect on surface finish when machining the titanium base IMI 318 alloy. 


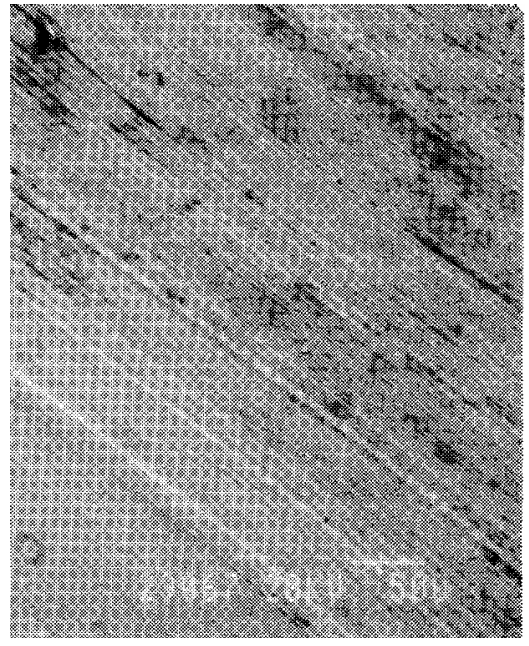

Figure 16. Feed marks generated when machining with SPRT tool are inclined at an angle to the vertical and is known as the trace angle. (After Wang, Ezugwu and Gupta, Tribology Transactions, 41, 9 (1998), 2, 289295).

Prolong machining tend to lower the surface roughness value, thus improving surface finish, as shown in Figure 17 (13). The ideal values (arithmetical mean value) of surface roughness produced under conventional turning can be obtained as: $\mathrm{Ra}=0.0321 \mathrm{~S}^{2} / r$, where $\mathrm{S}$ is the feed rate and $r$ is the nose radius. Figure 17 also shows that an increase in feed rate from $0.25 \mathrm{~mm} / \mathrm{rev}$ to $0.4 \mathrm{~mm} / \mathrm{rev}$ only gave a slight deterioration in surface finish generated, unlike in conventional turning. This can be attributed to the smearing action between the tool and the workpiece when machining at higher feed rate. Deterioration in the machined surface occurred when machining with an increase in inclination angle from 45 to $60^{\circ}$, Figure 18, due to a corresponding reduction in the effective nose radius of the round inserts (11). Analysis of the machined surfaces show minimal structural defects on the Inconel 718 surfaces produced with the SPRT inserts (Figure 19b) unlike the pronounced plastic deformation and nucleation observed after machining under conventional turning (Figure 19a). The overall surface finish produced with the SPRT can be greatly affected by the stability of the rotary cutting system. A major problem with the rotary cutting technique is maintaining the concentricity or circularity of the cutting edge during machining. This can however be maintain by effective damping of the SPRT system to ensure consistency of the machining performance.

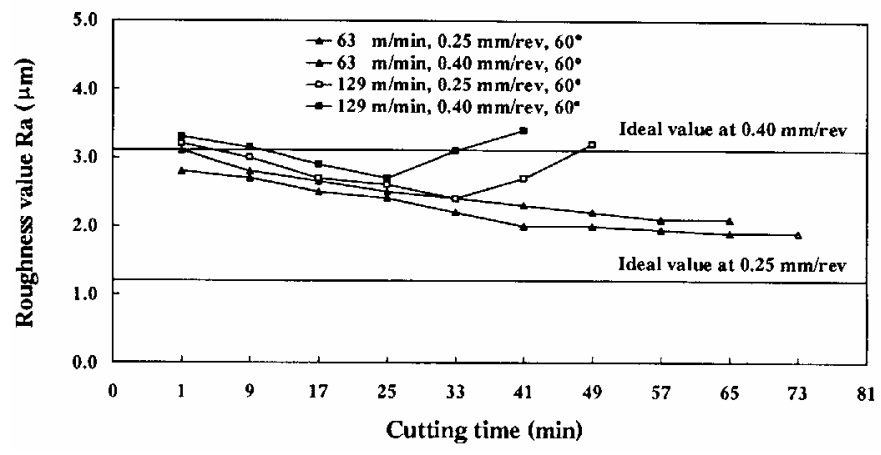

Figure 17. Surface roughness vs. cutting time when machining IMI318 with the SPRT at a DOC of $0.25 \mathrm{~mm}$. (After Wang, Ezugwu and Gupta, Tribology Transactions, 41, 9 (1998), 2, 289-295).

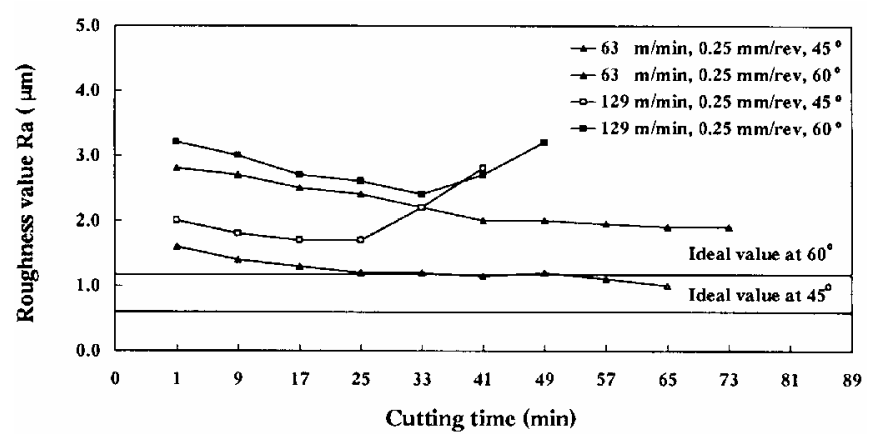

Figure 18. Surface roughness vs. cutting time when machining IMI with the SPRT at a feed rate of $0.25 \mathrm{~mm} / \mathrm{rev}$ and DOC of $0.25 \mathrm{~mm}$. (After Wang, Ezugwu and Gupta, Tribology Transactions, 41, 9 (1998), 2, 289-295).

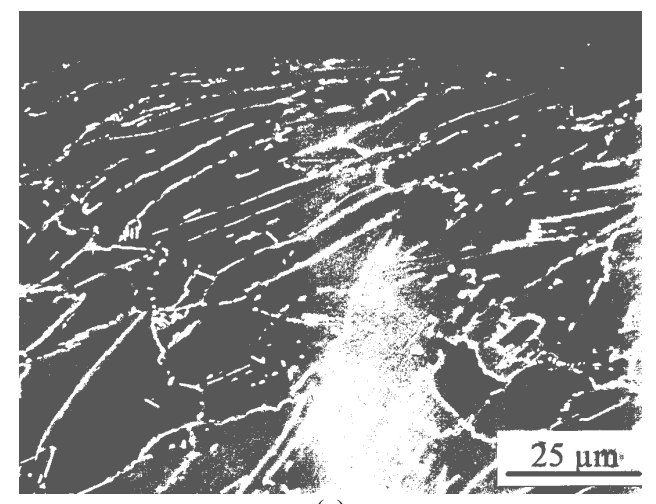

(a)

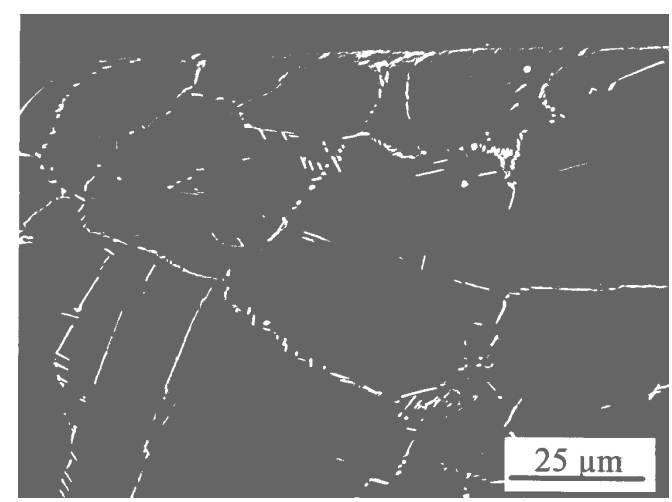

(b)

Figure19. Micrograph of Inconel 718 after machining at speed : $50 \mathrm{~m} / \mathrm{min}$ and feed: $0.25 \mathrm{~mm} / \mathrm{rev}$. (Wang, Ezugwu and Gupta, Tribology Transactions, 41, 9 (1998), 2, 289-295).

\section{High Pressure Coolant Supply}

The idea of delivering coolant under high pressure to the cutting region in order to increase tool life during machining began in early 1950 s (15). The primary objective of this machining technique is to significantly reduce the temperature generated at the tool-workpiece and tool-chip interfaces when cutting at higher speed conditions. This is achieved by directing coolant under high pressure at the chip-tool interface (Figure 20). This process can also achieve high chip breakability and control through increased chip upcurl and compressive stress. Flood cooling of the cutting zone can effectively reduce the cutting temperature when machining at lower speed conditions with significant sliding region and where relatively low cutting temperatures are generated. The coolant also acts as a lubricant, thus minimising friction and lowering component forces 
and consequently tool life. There is very limited access of the coolant to the tool-workpiece or tool-chip interfaces which are mainly under seizure condition when machining at high speed conditions. Coolants tend to be vaporised by the high temperature generated close to the tool edge, forming a high temperature blanket that renders their cooling effect ineffective. The film boiling temperatures of conventional cutting fluids is about $350^{\circ} \mathrm{C}(16)$.

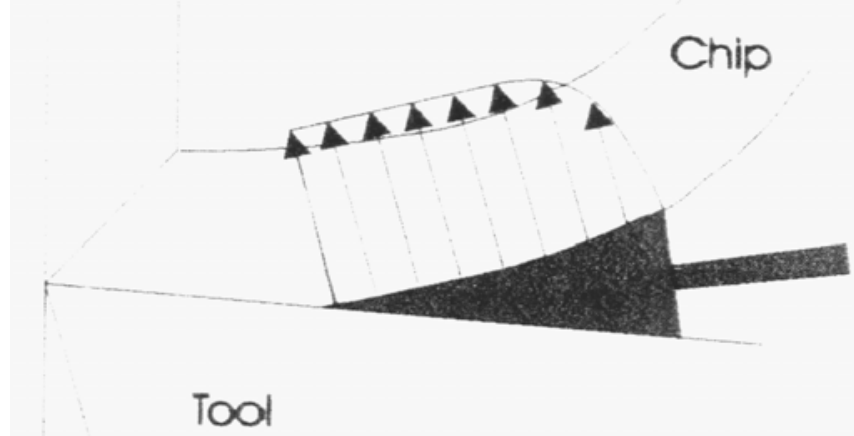

Figure 20. Coolant jet under high pressure is capable of creating a hydraulic jet.

Ability to deliver coolant at high pressure very close to the critical point on the secondary shear zone can improve machinability at higher speed conditions. The credibility of this technique of coolant delivery has been thoroughly investigated over the years. Initially, this technique was unpopular because of associated equipment cost and also the fact that low speed machining was the preferred mode of production as machine tools were not capable of high speed machining applications. The manufacturing industry have recently adopted a more radical approach to increasing the rate of production and high pressure coolant delivery technique is a viable means of achieving this strategy in addition to providing an effective removal (by flushing) of the chips from the cutting area. The high speed coolant jet traverses the surface faster, thus significantly lowering the film boiling action of the coolant at the cutting area. This consequently minimises heat transfer to the cutting tool. The high pressure coolant jet creates a hydraulic wedge between the tool and the workpiece, penetrating the interface with a speed exceeding that required even for high speed machining and also alters the chip flow conditions (17). The penetration of the high energy jet into the tool-chip interface reduces the temperature gradient and eliminates the seizure effect, offering an adequate lubrication at the tool-chip interface with a significant reduction in friction.

Up to 7 folds improvement in tool life can be achieved when machining nickel base, Inconel 718, alloy with coated carbide tools at speeds up to $50 \mathrm{~m} / \mathrm{min}$ (Table 5) with high pressure coolant supplies while lower tool life was recorded when machining with ceramic tools (Table 6) with high pressure coolant supplies (18-20). Rapid failure of ceramic tools when machining with higher pressure coolant supply and at higher cutting conditions can be associated with a significant reduction in the chip-tool contact length/area (Figure 21). This reduction has negligible effect on cutting forces, resulting in higher compressive stresses on the cutting edge that tend to accelerate notching and/or tool fracture during machining, Figure 22 (20). Table 6 is a summary of the percentage drop in tool life when machining Inconel 718 with $\mathrm{SiC}$ whisker reinforced alumina ceramic tools at high speed conditions and with high pressure coolant supplies relative to conventional coolant supply (19). Ceramic tools are more susceptible to failure by mechanical action such as notching and micro-chipping at the cutting edge due to their relatively poor mechanical properties, especially fracture toughness. These failure modes occur on a random basis, leading to inconsistency in tool performance accelerated by fluctuations in thermal and mechanical properties when machining with high pressure coolant supply. Ceramic tools also encounter severe notching on the tool rake face after machining with high pressure coolant supply due to water jet impingement or hydrodynamic erosion $(19,21)$.

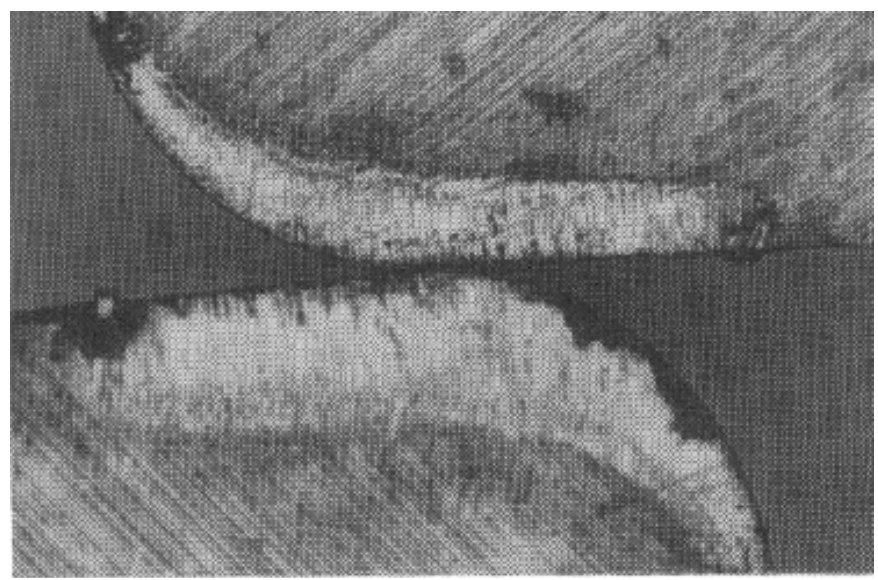

Figure 21. Rake faces of worn inserts showing the reduction in the tool chip contact length when cutting with high pressure coolant supply (top). (After Ezugwu et. al. Lubrication Engineering, 47 (1991), 9, 751-757).

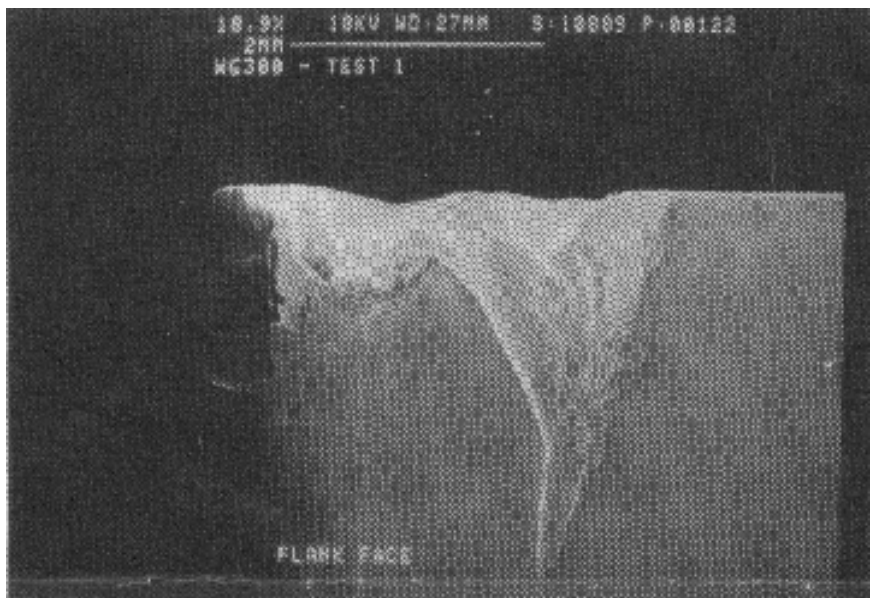

Figure 22. Severe notching at the depth of cut region of a ceramic tool after machining Inconel 901. (After Ezugwu et. al. Lubrication Engineering, 47 (1991), 9, 751-757).

Table 5. Percentage improvement in tool life relative to conventional coolant supply after machining Inconel 718 with coated carbide tool (After Ezugwu and Bonney, in: Proceedings of AMPT2003, 8-11 July 2003, Dublin, Ireland).

\begin{tabular}{|c|c|c|c|c|}
\hline $\begin{array}{c}\text { Speed } \\
\left(\mathrm{m} \mathrm{min}^{-1}\right)\end{array}$ & $\begin{array}{c}\text { Feed rate } \\
\left(\mathrm{mm} \mathrm{rev}^{-1}\right)\end{array}$ & 110 bar & 150 bar & 203 bar \\
\hline 20 & 0.25 & 8 & 9.8 & -33.8 \\
\hline 30 & 0.25 & 87.7 & 50.6 & 64.1 \\
\hline 50 & 0.25 & 335.0 & 411.1 & 462.8 \\
\hline 20 & 0.3 & 8.6 & 11.5 & -43.9 \\
\hline 30 & 0.3 & 27.05 & 95.2 & 104.5 \\
\hline 50 & 0.3 & 517.6 & 647.2 & 739.8 \\
\hline
\end{tabular}


Table 6. Percentage drop in tool life relative to conventional coolant supply when machining Inconel 718 with $\mathrm{SiC}$ whisker reinforced alumina ceramic tool. (After Ezugwu and Bonney, Effect of High-pressure Coolant Supplies when Machining Nickel-base, Inconel 718, Alloy with Ceramic Tools, To be published in Tribology Transactions).

\begin{tabular}{|c|c|c|c|c|}
\hline $\begin{array}{c}\text { Speed } \\
\left(\mathrm{m} \mathrm{min}^{-1}\right)\end{array}$ & $\begin{array}{c}\text { Feed rate } \\
\left(\mathrm{mm} \mathrm{rev}^{-1}\right)\end{array}$ & 110 bar & 150 bar & 203 bar \\
\hline 200 & 0.15 & -48.6 & -51.6 & -49.6 \\
\hline 250 & 0.15 & -45.7 & -38.8 & -69.7 \\
\hline 300 & 0.15 & -44.7 & -34.1 & -63.1 \\
\hline 200 & 0.25 & -4.5 & -35.0 & -35.0 \\
\hline 250 & 0.25 & -47.9 & -63.0 & -61.7 \\
\hline 300 & 0.25 & -68.8 & -67.5 & -65.6 \\
\hline
\end{tabular}

An increase in coolant pressure generally improved tool life when machining Inconel 718 with coated carbide tools. Effective chip segmented can be achieved when machining with high pressure coolant supply unlike long continuous chips produced when machining with conventional coolant supply (Figure 23).
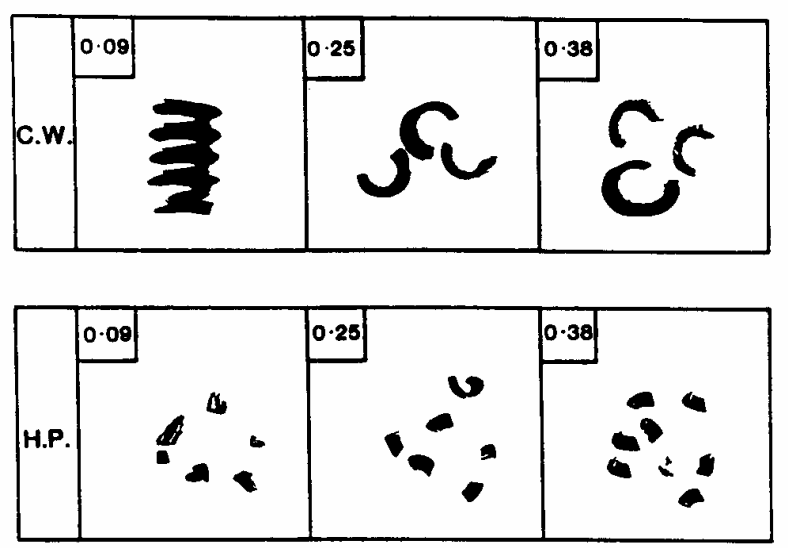

FEEDRATE (mm/rev)

Figure 23. Swarf samples produced when machining Inconel 901 at various cutting conditions using both the high pressure and conventional coolant supplies. (After Ezugwu et. al. Lubrication Engineering, 47 (1991), 9, 751-757).

The benefits of high pressure coolant supply seem more obvious when machining commercially available titanium, Ti6Al4V, alloy (IMI 318) with coated and uncoated carbide tools as well as with Polycrystalline Diamond (PCD) tools as illustrated in Figures 24-26. These figures clearly show that remarkable tool life can be achieved with high pressure coolant supplies and that there is negligible difference between coated and uncoated carbide tools in terms of recorded tool life. These improvements can be achieved without compromising the surface finish generated, circularity and hardness variation of the machined surfaces. Cubic boron nitride and ceramic cutting tools are not recommended for high speed machining of titanium alloys with high pressure coolant supply as they tend to suffer excessive nose wear and severe chipping and/or fracture of the cutting edge. The influence of cutting speed on temperature generated when machining titanium alloy with straight grade (K10) carbide can be illustrated with data contained in Table 7 . Increase in cutting speed generally resulted in higher cutting temperature. It is, however, important to note that lower temperature was generated when machining at $500 \mathrm{~m} / \mathrm{min}$, relative to that recorded at 450 $\mathrm{m} / \mathrm{min}$. This can be associated with the erosion of the cutting edge due to severe thermal wear at the cutting edge (Figure 27).

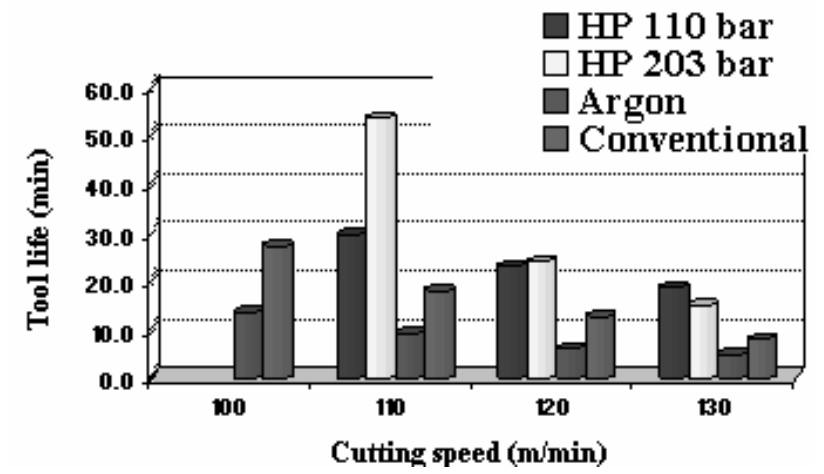

Figure 24. Recorded Tool life when machining titanium alloy with the Uncoated Carbide inserts under coolant pressures of 110 and 203 bar, conventional coolant flow and in an argon enriched environment at various cutting speeds.

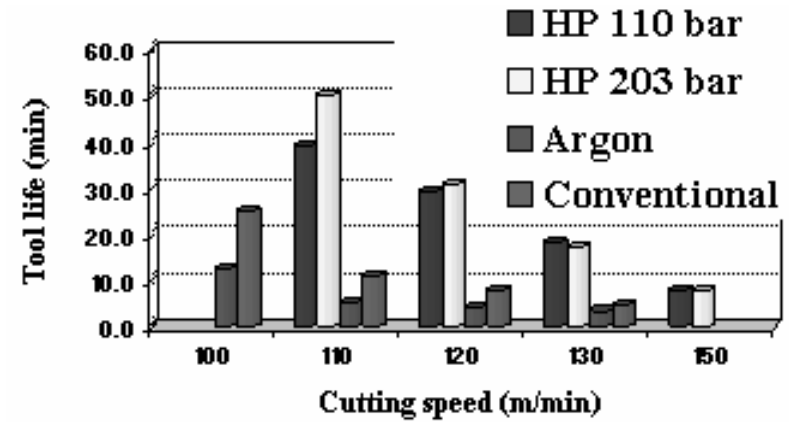

Figure 25. Recorded Tool life when machining titanium alloy with the Coated Carbide inserts under coolant pressures of 110 and 203 bar, conventional coolant flow and in an argon enriched environment at various cutting speeds.

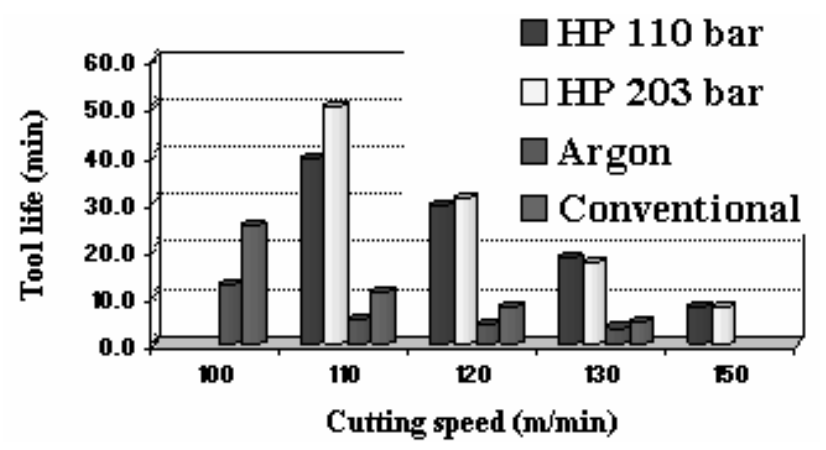

Figure 26. Recorded tool life when machining Ti-6Al-4V alloy with PCD inserts under coolant pressures of 110 and 203 bar and conventional coolant flow at various cutting speeds.

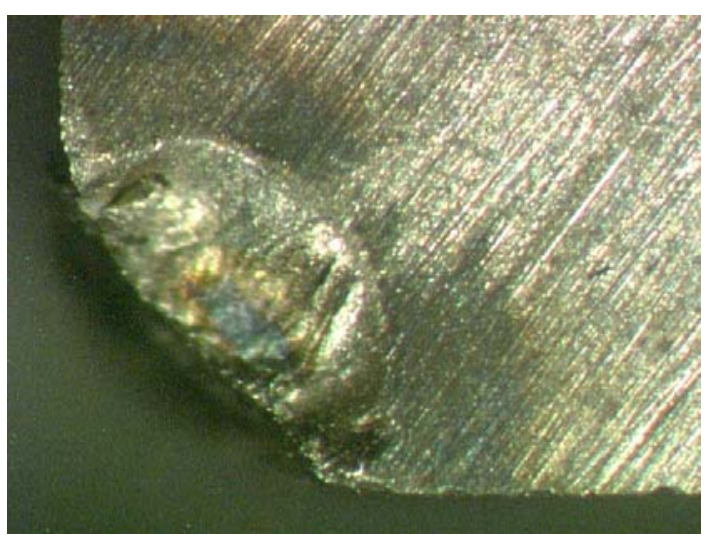

Figure 27. Wear of the rake face after a few second machining of titanium alloy at $500 \mathrm{~m} / \mathrm{min}$ (After Yamani et. al. 2002). 
Table 7. Influence of cutting speed on the cutting temperature. (After Yamani et. al. 2002).

\begin{tabular}{|c|c|c|}
\hline Cutting speed, $\mathrm{m} / \mathrm{min}$ & EMF, $\mathrm{mV}$ & Temperature, deg. $\mathrm{C}$ \\
\hline 50 & 9.0 & 612 \\
\hline 100 & 11.9 & 763 \\
\hline 150 & 13.5 & 853 \\
\hline 200 & 14.7 & 924 \\
\hline 250 & 16.1 & 1020 \\
\hline 300 & 16.6 & 1057 \\
\hline 350 & 16.8 & 1075 \\
\hline 400 & 17.6 & 1138 \\
\hline 450 & 18.4 & 1219 \\
\hline 500 & 18.3 & 1215 \\
\hline
\end{tabular}

\section{Minimum Quantity Lubrication (MQL)}

It has long been observed that cutting fluids if not disposed off properly may adversely affect the environment. Machine operators in contact with cutting fluid develop severe reactions on the skin in addition to fumes, smoke, bacterial and odours. To solve some of these problems, "clean machining" is now being emphasised. This concept is defined as machining with the use of minimum amount of coolants and/or the use of environmentally acceptable coolants (22). Minimal Quantity Lubrication (MQL) technology involves the application of very small amount of water and soluble oil, 6-100 ml $\mathrm{h}^{-1}$, delivered in a compressed air stream, directed at the tool cutting edge $(23,24)$. Encouraging results had been observed in grinding, milling and turning applications. These improvements in machining can be attributed to the lubricating oil that was able to get very close to the tool-chip and tool-workpiece interfaces under pressure, therefore reducing friction and component forces generated during machining. Temperature reduction at the cutting zone in MQL systems is achieved mainly by the cooling effect of the compress air and partially by evaporation. Significant amount of heat is absorbed to effect the evaporation of the lubricants, thus contributing to a significant temperature reduction at the cutting zone. Pressure welding of chips to the cutting edge is the main cause of tool failure when milling titanium alloys with HSS tools. With MQL this failure mode can be drastically reduced causing significant improvement to surface finish of the machined components. The MQL system has shown encouraging potentials for precision machining at low feed and high speed conditions (25). The main disadvantage of using this system is mist generation, which pose a health hazard to operators. This hazard can however be minimised with good mist extractors.

\section{Cryogenic Cooling}

Cryogenic cooling is an efficient way of maintaining the temperature at the cutting interface well below the softening temperature of the cutting tool material. This technology is exploited mainly in the grinding industry because of the high specific energy requirements which results in high grinding zone temperature which if not properly controlled will lead to surface damage. For example alterations in the physical and chemical characteristics of the top layers of ground surfaces, introduction of tensile residual stresses and surface and sub-surface cracks which are detrimental to the efficient functioning of machined components. The principle of cryogenic cooling in grinding involves directing a jet of liquefied gases under pressure into the grinding zone. Commonly used coolant is liquid nitrogen (LN2) because of its low cost and the fact that it does no harm to the environment. When turning a high strength reaction bonded silicon nitride (RBSN) with CBN cutting tool, it was found that the maximum temperature generated at the cutting interface was only $829^{\circ} \mathrm{C}$ as against $1153^{\circ} \mathrm{C}$ in dry machining (26). This temperature is far below the softening temperature $\left(1500^{\circ} \mathrm{C}\right)$ of $\mathrm{CBN}$ tool material, hence the improved tool performance obtained with the LN2 cooling system. It has also been shown that in turning applications directing the LN2 coolant jet directly to the cutting interface at the rake face and the secondary flank face simultaneously improve tool performance significantly, Figure $28(27,28)$. In cryogenic machining high cutting and trust forces are generated than in conventional and flood cooling or dry machining applications (Figure 29). This anomaly is attributed to the fact that sub zero temperatures has the consequence of increasing hardness and strength of the work material, hence higher forces are generated with cryogenic cooling (29). Tool wear rates when machining titanium alloy Ti-6Al-4V with cemented carbide using LN2 and under conventional cooling at a cutting speed of 132 $\mathrm{m} \mathrm{min}{ }^{-1}$, feed rate of $0.2 \mathrm{~mm} \mathrm{rev}^{-1}$ and a depth of cut of $1.0 \mathrm{~mm}$ showed a five fold increase in flank wear for tools subjected to the conventional cooling (30).

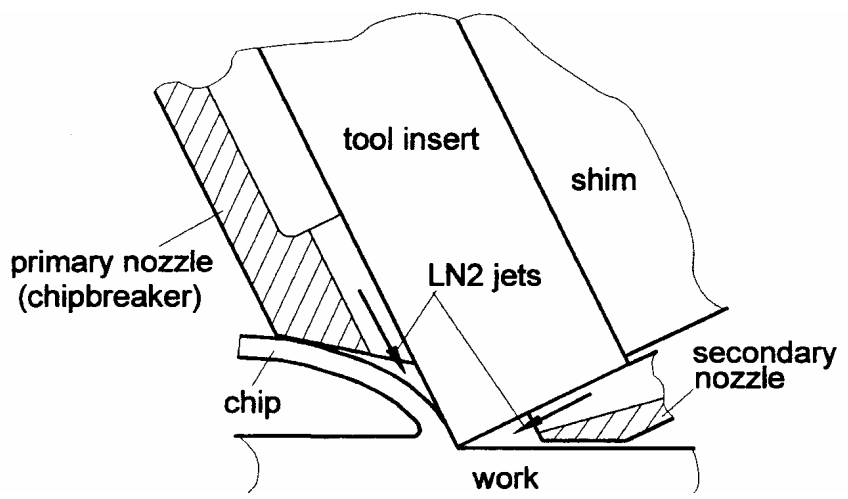

Figure 28. Duel-nozzle system for localized LN2 supply (After Hong et. al. Int. J. Mach. Tools Manufact. 41(2001) 1417-1437).

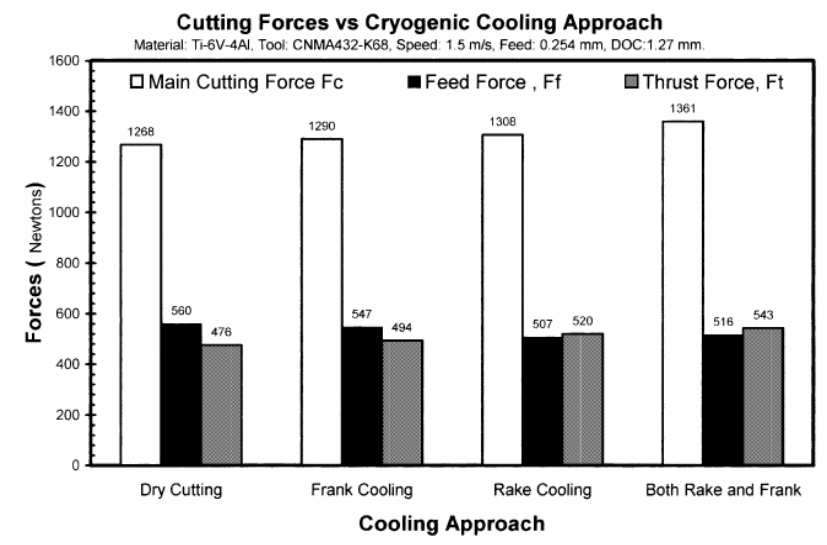

Figure 29. Cutting forces in different cooling condition at $1.5 \mathrm{~m} \mathrm{~s}-1(300 \mathrm{ft}$ min-1) (After Hong et. al. International Journal of Machine Tools \& Manufacture, Vol. 41, 2001, pp 2271-2285).

\section{Conclusions}

1. Machining of aero-engine alloys generate high temperatures at the cutting edge which impair the performance of various cutting tool materials.

2. Commercially available cutting tool materials are currently being applied at moderate speed conditions when machining aero-engine alloys, hence lower machining productivity.

3. SPRT can significantly improve tool life when the cutting tool is set at the optimum inclination angle.

4. Machining technologies such as high pressure coolant supply, Minimum Quantity Lubrication and Cryogenic 
cooling are designed specifically to minimising the temperature generated at the tool-workpiece and tool-chip interfaces. These developments ensure that cutting tool materials maintain their properties at higher cutting conditions in order to ensure that efficient and economic machining of difficult-to-cut aero-engine alloys is achievable.References

Seco Technical guide, Turning Difficult-To-Machine Alloys

S. Miller, Advanced materials means advanced engines, Interdisciplinary Science Review, 21 (2) (1996) 117-129

R. R. Boyer, An overview on the use of titanium in aerospace industry, Journal of Material Science and Engineering, Part A213 (1996) 103-114

E. O. Ezugwu, Z. M. Wang, Titanium alloys and their machinability- a review, Journal of Materials Processing Technology, Vol. 68, 1997, pp 262274

E. O. Ezugwu, J. Bonney, Y. Yamane, An overview of the machinability of aeroengine alloys, Journal of Material Processing Technology 134 (2003) 233-253

B. M. Kramer, On Tool Materials for High Speed Machining, Journal of Engineering for Industry, Vol. 109, May 1987, pp 87-91

E. A. Almond, Towards improved tests based on fundamental properties, Proceedings of the International Conference on Improved Performance of Tool Materials, the National Laboratory and the Metals Society, Teddington, Middlesex, April 28-29, 1981, pp 161-169

F. Klocke, W. Konig, and K. Gerschwiler, Advanced Machining of Titanium and Nickel-base Alloys, Advanced Manufacturing Systems and Technology, CISM Courses and Lectures No. 372, Springer Verlag, Wien New York, 1996, pp 7-21

E. J. A. Armarego, Computer Aided Predictive models for fundamental Rotary Tool Cutting Process, Annals of the CIRP, 42, 1, (1993) 49-54

W. Y. Chen, Machining of Hardened Steel Using Superhard Tooling, PCD and CBN Tipped Rotary Cutting Tools, Ph.D Thesis, University of Birmingham, UK, 1993

X. Chang, W. Chen, X. Pang and G. Zhong, Selection of cutting regime for self-propelled rotary cutting tools, Procedings of the Institution of Mechanical Engineers, Part B, 209(B1) (1995) 63-66

P. Chen, Cutting temperature and forces in machining of high performance materials with self-propelled rotary tool, Japanese Sociaty of Mechanical Engineers, 35 (1) (1992) 180-185

Z. M. Wang, E. O. Ezugwu, and A. Gupta, Evaluation of a SelfPropelled Rotary Tool in the Machining of Aerospace Materials, Tribology Transactions, Vol. 41, No. 2, 1998, pp 289-295

E. O. Ezugwu, K. A. Olajire and Z. M. Wang, Wear Evaluation of a Self-Propelled Rotary Tool when Machining Titanium, IMI 318, Alloy, in:
Proceedings of the Institution of Mechanical Engineers, Vol. 216, Part B, 2002, pp. 891-897

R. J. S., Pigott and A. T. Colwel, Hi-Jet System for Increasing tool life, SAE Quarterly Transactions, Vol. 6, No. 3, July 1952, pp. 547-566

S. Paul, A. B. Chattopadhyay, Effect of cryogenic cooling by liquid nitrogen jet on forces, temperature and surface residual stresses in grinding steels, Cryogenics, Vol.35, No. 8, 1995, pp 515-523

M. Mazurkiewicz, Z. Kubala, J. Chow, Metal Machining with HighPressure Water-Jet Cooling Assistance - A New Possibility, Journal of Engineering for Industry, Vol. 111, 1989, pp 7-12

E. O. Ezugwu and J. Bonney, Effect of High-pressure Coolant Supply when Machining Nickel-base, Inconel 718, Alloy with Coated Carbide Tools. in: Proceedings of AMPT2003, 8-11 July 2003, Dublin, Ireland

E. O. Ezugwu and J. Bonney, Effect of High-pressure Coolant Supplies when Machining Nickel-base, Inconel 718, Alloy with Ceramic Tools, STLE (2003)

E. O. Ezugwu, A. R. Machado, I. R. Pashby, and J. Wallbank, "The Effect of High-Pressure Coolant Supply When Machining a Heat-Resistant Nickel-Based Superalloy," Lubrication Engineering, Vol. 47, No. 9, 1991, pp 751-757

B. S. Mann, V. Arya, An experimental study to correlate water-jet impingement erosion resistance and properties of metallic materials and coatings, Wear, Vol. 253, 2002, pp 650-661.

M. A. El Baradie, Cutting Fluids: Part II. Recycling and Clean Machining, Journal of Material Processing Technology 56 (1996) 798-806

D. U. Braga and A. E. Diniz, Using a minimum quantity of lubricant (MQL) and diamond coated tool in the drilling of aluminium-silicon alloys, Journal of Material Processing Technology 122 (2002) 127-138

V. Derflinger, H. Brandle, H. Zimmermann, New hard/lubricant coating for dry machining, Surface and Coating Technology, 1999, Vol. 113, pp286292

A. R. Machado, J. Wallbank, The effect of extremely low lubricant volumes in machining, Wear, Vol. 210, pp 76-82

Z. Y. Wang, K. P. Rajurkar, Wear of CBN Tool in turning of silicon nitride with cryogenic cooling, International Journal of Machine Tools Manufacture, Vol. 37, No. 3, 1997, pp 319-326

S. Y. Hong, Y. Ding, Cooling approaches and cutting temperatures in cryogenic machining of Ti-6Al-4V, International Journal of Machine Tools \& Manufacture, Vol. 41, 2001, pp 1417-1437

S. Y. Hong, I. Markus, W. Jeong, New cooling approach and tool life improvement in cryogenic machining of titanium alloy Ti-6Al-4V, International Journal of Machine Tools \& Manufacture, Vol. 41, 2001, pp 2245-2260

S. Y. Hong, Y. Ding, W. Jeong, Friction and cutting forces in cryogenic machining of Ti-6Al-4V, International Journal of Machine Tools \& Manufacture, Vol. 41, 2001, pp 2271-2285

Z. Y. Wang, K. P. Rajurkar, Cryogenic machining of hard-to-cut materials, Wear, Vol. 239, 2000, pp 168-175. 